14

Fun and Games with Fluorous Chemistry

József Rábai

14.1

Introduction: Where Does the Fun Come From?

Much of the fun emanates from the unique phase properties of fluorocarbons, which are governed by thermodynamics. The extraordinary solvent properties of fluorocarbons came to light in the late 1940s, as illustrated by the following citation [1]: "The large molal volumes of the fluorocarbons compared with the corresponding hydrocarbons leads to unusually low 'internal pressures' or 'cohesive energy densities', while their high molecular weights aid in maintaining them in the liquid state; the net result of which is to make many of their solutions with ordinary liquid hydrocarbons deviate from Raoult's law to such an extent as to form two liquid phases, a state of affairs comparatively rare among non-polar liquids."

The thermodynamic theory of non-electrolyte solutions, as developed by van Laar, Hildebrand, and Scatchard, in its simplest form uses solubility parameters $(\delta)$, molal volumes $(V)$, temperature, mole fractions and volume fractions to account for the molal free energy of a component in a mixture of two non-polar liquids. Furthermore, this theory allows the estimation of liquid/liquid miscibilities and critical solution (consolute) temperatures $\left(T_{\mathrm{c}}\right)$, using Eq. (1) [2]:

$$
4 R T_{\mathrm{c}}=\left(V_{1}+V_{2}\right)\left(\delta_{1}-\delta_{2}\right)^{2}
$$

Increasing differences in solubility parameters will result in higher critical solution temperatures, or in other words bring about lower miscibility. Thus, $\mathrm{C}_{6} \mathrm{~F}_{11} \mathrm{CF}_{3}$ and $\mathrm{CCl}_{4}$ yield a one-phase system at $27{ }^{\circ} \mathrm{C}$, while the more polar non-fluorous solvents benzene and chlorobenzene afford single phases at $85{ }^{\circ} \mathrm{C}$ and $127{ }^{\circ} \mathrm{C}$, respectively. All systems were assayed easily and precisely in sealed glass tubes, as reported (Table 14-1) [2].

The above theory also predicts that the best solubility or miscibility is observed for components with similar molal volumes, provided their solubility parameters are equal. This is a simplified thermodynamic expression of the "like dissolves like" principle [3]. Consciously or not, synthetic and separation chemists make frequent use of this theory of regular solutions in selecting solvents for reactions and workups.

This chapter will describe some experiments in which three liquid phase systems are converted into two-phase systems, and with further temperature increases into one-phase systems. Since the liquid layers in these systems can be colored independently according to the wish of the person who performs the experiments, many other variations are possible.

Handbook of Fluorous Chemistry. Edited by John A. Gladysz, Dennis P. Curran, István T. Horvath Copyright @ 2004 WILEY-VCH Verlag GmbH \& Co. KGaA, Weinheim

ISBN: 3-527-30617-X 
Tab. 14-1. Critical (consolute) temperatures of solutions of perfluoromethylcyclohexane (component 1) [2]

\begin{tabular}{lllll}
\hline Solvent & $\boldsymbol{V}\left(\mathbf{c m}^{\mathbf{3}} \mathbf{~ m o l}^{-\mathbf{1}}\right)$ & $\boldsymbol{T}_{\boldsymbol{c}, \text { obs }}(\boldsymbol{K})$ & $\boldsymbol{\delta}_{\mathbf{2}}\left(\mathbf{c a l} \mathbf{c m}^{-\mathbf{3}}\right)^{\mathbf{1 / 2}}$ & $\boldsymbol{\delta}_{\mathbf{1}, \text { calcd }}\left(\mathbf{c a l} \mathbf{c m}^{-\mathbf{3}}\right)^{\mathbf{1 / 2}}$ \\
\hline $\mathrm{C}_{6} \mathrm{~F}_{11} \mathrm{CF}_{3}$ & 195 & - & - & - \\
$\mathrm{CCl}_{4}$ & 97 & 300 & 8.6 & 5.8 \\
$\mathrm{CHCl}_{3}$ & 81 & 323.5 & 9.0 & 6.0 \\
$\mathrm{C}_{6} \mathrm{H}_{6}$ & 89 & 358.5 & 9.15 & 6.0 \\
$\mathrm{C}_{6} \mathrm{H}_{5} \mathrm{CH}_{3}$ & 102 & 362.0 & 8.9 & 5.8 \\
$\mathrm{C}_{6} \mathrm{H}_{5} \mathrm{Cl}$ & 107 & 400.0 & 9.5 & 6.3 \\
\hline
\end{tabular}

The experiments included here are the author's favorites, because they call attention to keywords and concepts such as solubility [4], extraction [4], partition [4, 5], solvatochromism [4], fluorophilicity [5], fluorous gold nanoclusters [6], temperature dependent miscibility [7], density [8], volatility [8], polarizability [8], lipophilicity [8], fluorine substituent effects [8] and perfluoroalkylation [9]. Owing to space limitations, experiments are described in the most compact way and references given for more detailed analyses.

This chapter also features the preparation of fluorous and organic dyes, as well as a threecomponent three-phase system and a four-component three-phase system. Two-phase systems are incorporated in the experiments with the four-component three-phase systems ( $3 \rightarrow 2 \rightarrow 1$ or $1 \rightarrow 2 \rightarrow 3$ ), which equilibrate with one-phase systems upon heating and reform three-phase systems upon cooling.

14.2

Synthesis of Dyes for Fluorous and Organic Phases

14.2.1

How to Make the "Blue Dye": The Taming of Aromatic Perfluoroalkylations

The story of the fluorocarbon soluble blue dye is recalled by the author after a personal talk with Tiers [10], who invented the first perfluoroalkylation method for aromatic compounds [9]:

$$
\mathrm{ArH}_{m}+2 x \mathrm{R}_{\mathrm{fn}} \mathrm{I} \rightarrow \operatorname{ArH}_{m-x}\left(\mathrm{R}_{\mathrm{fn}}\right)_{x}+x \mathrm{I}_{2}+x \mathrm{R}_{\mathrm{fn}} \mathrm{H}
$$

Accordingly, an aromatic compound is mixed with an excess of perfluoroalkyl iodide, sealed in a Carius tube, and heated at high temperature within a brass protecting tube for several hours. The Carius tube is subsequently cooled in an acetone-dry ice bath, still within the brass safety container, and then the tip is inserted into rubber tubing and cracked with the aid of a hammer (Figure 14-1). Tiers refers to this sequence as a "brutal perfluoroalkylation".

In the early 1950s it was thought that perfluorocarbon based hydraulic fluids used in submarines should be colored to improve on-board safety by making them more easily distinguishable from liquid fuels. A dye had been prepared from copper phthalocyanine and perfluoroheptyl iodide under the above conditions. Since the byproducts of the above equation, $\omega$-hydroperfluoroalkanes and iodine, are more volatile than the educts, a significant 


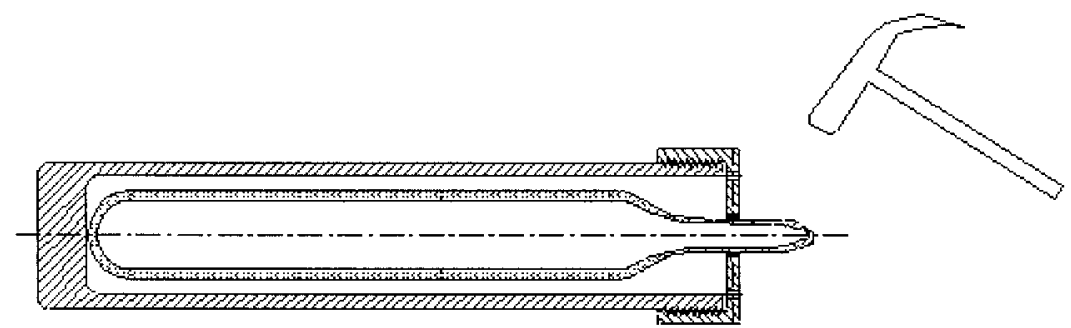

Fig. 14-1. Safe opening of a Carius tube. Redrawn from a sketch by George van Dyke Tiers [10].

pressure increase is expected at higher conversions. Accordingly, this procedure is not only brutal but hazardous.

The product obtained forms brilliant blue solutions in fluorocarbons and benzotrifluoride, and is suitable for staining Teflon ${ }^{\circledR}$ at higher temperatures, near its glass transition point [9].

Other methods disclosed later provide lower reaction temperatures and higher yields based on perfluoroalkyl iodides [11-13]. However, in one of these [11] the increased yields are at the expense of the use of a peroxide reagent in stoichiometric amounts, which limits applications due to the explosion hazards associated with this compound family. The other two methods are easy to apply under standard laboratory conditions. The addition of sodium acetate or potassium carbonate to the aromatic hydrocarbon and perfluoroalkyl iodide mixture suppresses or eliminates the formation of $\omega$-hydroperfluoroalkanes and iodine side products, resulting in less pressure increase $[12,13]$.

The "blue dye" of the initial FBS paper [14] was made analogously to the original Tiers procedure. However, for the benefit of the readers a milder, safer and "less brutal" method is elaborated [15b]. Here melting point capillary tubes are substituted for the Carius tube, and household aluminum wrapping foil is used instead of the protecting brass tube of Figure 14-1.

Perfluorodecyl Cobalt(II)phthalocyanines. Direct Alkylation with Perfluorodecyl lodide

\section{Reaction 14-1}
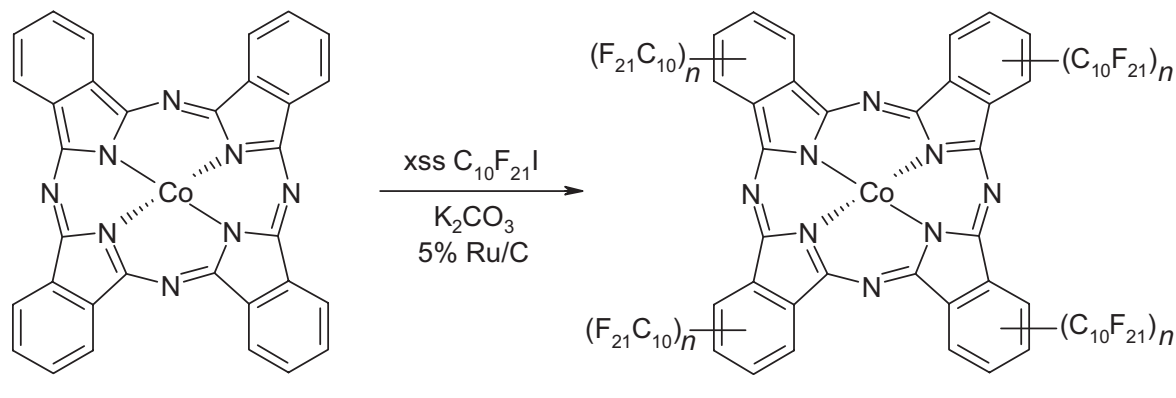

$$
n=1,2, \ldots
$$


Reagents

Perfluorodecyl iodide [423-62-1], cobalt(II)phthalocyanine [3317-67-7], and ruthenium, 5 wt.\% on carbon are commercially available.

\section{Experimental Procedure}

Cobalt(II)phthalocyanine $(0.088 \mathrm{~g}, 0.154 \mathrm{mmol}), \mathrm{C}_{10} \mathrm{~F}_{21} \mathrm{I}(1.0 \mathrm{~g}, 1.5 \mathrm{mmol}), \mathrm{K}_{2} \mathrm{CO}_{3}(0.12 \mathrm{~g}$, $0.87 \mathrm{mmol})$ and $5 \% \mathrm{Ru} / \mathrm{C}(0.026 \mathrm{~g})$ were mixed in a mortar. Then five melting point capillary tubes (approximately $10 \mathrm{~cm}$ long and $1 \mathrm{~mm}$ inner diameter) were filled with this mixture to a height of ca. $2 \mathrm{~cm}$ and sealed in a Bunsen flame. The capillaries were bunched together and wrapped with ten turns of aluminum foil. The ends of the foil were folded back from the capillary tips. This package was heated in the oven of a "retired" gas chromatograph at $200{ }^{\circ} \mathrm{C}$ for two days. The bundle was cooled to room temperature and broken into two halves by bending at the middle. The colored pieces of the capillaries were ground in a mortar and extracted with a few $\mathrm{mL}$ of benzotrifluoride. The resulting blue solution was filtered through a cotton plug in a Pasteur pipette. The filtrate was treated at room temperature with an excess of $\mathrm{NaBH}_{4}(0.05 \mathrm{~g})$ dissolved in methanol $(0.5 \mathrm{~mL})$ to convert the unreacted $\mathrm{C}_{10} \mathrm{~F}_{21} \mathrm{I}\left(\mathrm{bp} \sim 200{ }^{\circ} \mathrm{C}\right.$ ) into $\mathrm{C}_{10} \mathrm{~F}_{21} \mathrm{H}$ (bp $\sim 160{ }^{\circ} \mathrm{C}$ ), which is easier to remove on evaporation. The mixture was evaporated to dryness and the residue extracted with hot FC84. Filtration and evaporation yields approximately $0.1 \mathrm{~g}$ of the fluorous soluble "blue dye". About $1 \mathrm{mg}$ of this product is used to color the bottom layer of the system shown in Figure 14-2A.

14.2.2

Preparation of a Fluorophilic "Gold Dye": $\left(\mathrm{Au}_{m}\right)\left(\mathrm{HS}\left(\mathrm{CH}_{2}\right)_{3} \mathrm{R}_{\mathrm{f} 8}\right)_{n}$

Reaction 14-2

$$
\begin{gathered}
\mathrm{AuCl}_{4}{ }^{-}(\mathrm{aq})+\left(\mathrm{C}_{8} \mathrm{H}_{17}\right)_{4} \mathrm{~N}^{+}(\mathrm{BTF}) \rightarrow\left(\mathrm{C}_{8} \mathrm{H}_{17}\right)_{4} \mathrm{~N}^{+} \mathrm{AuCl}_{4}{ }^{-}(\mathrm{BTF}) \\
\mathrm{mAuCl}_{4}{ }^{-}(\mathrm{BTF})+n \mathrm{C}_{8} \mathrm{~F}_{17}\left(\mathrm{CH}_{2}\right)_{3} \mathrm{SH}(\mathrm{BTF})+3 m \mathrm{e}^{-} \\
\rightarrow 4 m \mathrm{Cl}(\mathrm{aq})+\left(\mathrm{Au}_{m}\right)\left(\mathrm{C}_{8} \mathrm{~F}_{17}\left(\mathrm{CH}_{2}\right)_{3} \mathrm{SH}\right)_{n}(\mathrm{BTF})
\end{gathered}
$$

\section{Reagents}

Hydrogen tetrachloroaurate(III) trihydrate [16961-25-4] and tetraoctylammonium bromide [63462-99-7] are commercially available, whereas perfluorooctylpropyl mercaptan can be prepared according to the literature procedure [16].

\section{Experimental Procedure}

A solution of $\mathrm{HAuCl}_{4} \cdot 3 \mathrm{H}_{2} \mathrm{O}(0.178 \mathrm{~g}, 0.457 \mathrm{mmol})$ in water $(15 \mathrm{~mL})$ was mixed with a solution of $\left(\mathrm{C}_{8} \mathrm{H}_{17}\right)_{4} \mathrm{NBr}(1.09 \mathrm{~g}, 2.0 \mathrm{mmol})$ in benzotrifluoride $(40 \mathrm{~mL})$. The two-phase mixture was shaken at room temperature until all the tetrachloroaurate was transferred into the organic layer. The water phase separated, and then the perfluorooctylpropyl mercaptan $\left(0.21 \mathrm{~g}, 0.42 \mathrm{mmol}\right.$ ) was added to the organic phase. A freshly prepared solution of $\mathrm{NaBH}_{4}$ 
$(0.19 \mathrm{~g}, 5 \mathrm{mmol})$ in water $(12.5 \mathrm{~mL})$ was added slowly ( $\sim 10 \mathrm{~min})$ with vigorous stirring. After further stirring for $3 \mathrm{~h}$, the organic phase was separated and washed with water $(3 \times$ $5 \mathrm{~mL})$. Then it was evaporated in vacuum using a rotavap and a water bath for heating $\left(50-60{ }^{\circ} \mathrm{C}\right)$. The dark residue was treated with dioxane $(40-50 \mathrm{~mL})$ at room temperature for $1 \mathrm{~h}$ to dissolve all components but the solid fluorous-thiol protected the gold nanoparticles. The latter product was isolated by suction filtration, washed with dioxane $(2 \times 5 \mathrm{~mL})$ and dried in a vacuum desiccator over phosphorous pentoxide. Yield: $140 \mathrm{mg}$ of a glittering black solid, stable to air, soluble in benzotrifluoride and fluorous solvents, insoluble in most organic solvents.

\section{Discussion}

Using a two-phase (water/toluene) reduction of $\mathrm{AuCl}_{4}{ }^{-}$by sodium borohydride in the presence of an alkanethiol results in the formation of solutions of 1-3 nm gold particles bearing a surface coating of thiol, as described by Brust et al. [17]. The first synthesis of fluorous thiol-protected gold nanoparticles, disclosed by Rábai et al., adopted the same strategy [6].

\subsection{3}

Preparation of an Organophilic "Gold Dye" $\left(\mathrm{Au}_{m}\right)\left(\mathrm{HS}\left(\mathrm{CH}_{2}\right)_{11} \mathrm{CH}_{3}\right)_{n}$

\section{Reaction 14-3}

Prepared according to the literature procedure [17]. For the equations, see 14.2.2 and substitute toluene for BTF, and $\mathrm{CH}_{3}\left(\mathrm{CH}_{2}\right)_{11} \mathrm{SH}$ for $n \mathrm{C}_{8} \mathrm{~F}_{17}\left(\mathrm{CH}_{2}\right)_{3} \mathrm{SH}$.

\section{Reagents}

Dodecanethiol [112-55-0] is commercially available.

\section{Experimental Procedure}

This preparation is conducted analogously to that in 14.2.2, but substituting toluene for BTF and 1-dodecanethiol $(0.085 \mathrm{~g}, 0.42 \mathrm{mmol})$ for the fluorous thiol. The workup was altered as follows. The solvent (toluene) was evaporated in vacuum, and the residue was consecutively treated with dioxane $(30 \mathrm{~mL})$ and benzene $(3 \times 30 \mathrm{~mL})$, with the evaporation of each solvent portion before the next was added. The dark residue was finally treated with acetone $(50 \mathrm{~mL})$, and the precipitate formed was isolated by filtration and washed with acetone $(3 \times 5 \mathrm{~mL})$. Yield: $100 \mathrm{mg}$ of glittering black solid, stable to air, soluble in benzotrifluoride and most organic solvents, insoluble in fluorocarbons.

\section{3}

\section{Fluorous Phase Systems for the Games}

Any of the solvent systems displayed in Table 14-2 are easy to assemble, however, appropriate chemical safety should be practiced during demonstrations. Although these experiments were designed to be as safe as possible, eye protection is a must in all cases. To avoid overheating the systems, and as a consequence of sudden boiling (splashes) in open vials or 
Tab. 14-2. Selected solvent miscibility data ${ }^{a, b}$

\begin{tabular}{|c|c|c|c|}
\hline Entry & Solvent system & Phase & Temp. $\left({ }^{\circ} \mathrm{C}\right)$ \\
\hline 1 & $\mathrm{FC}-72 /\left(\mathrm{CF}_{3}\right)_{2} \mathrm{CHOH}$ & One phase & $\mathrm{RT}$ \\
\hline 2 & $\mathrm{FC}-72 / \mathrm{CF}_{3} \mathrm{CH}_{2} \mathrm{OH}$ & $\begin{array}{l}\text { Two phase } \\
\text { One phase }\end{array}$ & $\begin{array}{l}\text { RT } \\
\text { on boiling }\end{array}$ \\
\hline 3 & FC-72/n-heptane & $\begin{array}{l}\text { Two phase } \\
\text { One phase }\end{array}$ & $\begin{array}{l}\mathrm{RT} \\
47 \mathrm{c}\end{array}$ \\
\hline 4 & FC-72/n-heptane $/ \mathrm{CH}_{3} \mathrm{NO}_{2}{ }^{\mathrm{d}}$ & $\begin{array}{l}\text { Three phase } \\
\text { Two phase }\end{array}$ & $\begin{array}{l}\text { RT } \\
\text { on warming }\end{array}$ \\
\hline 5 & FC-84/n-hexane & $\begin{array}{l}\text { Two phase } \\
\text { One phase }\end{array}$ & $\begin{array}{l}\mathrm{RT} \\
34^{\mathrm{c}}\end{array}$ \\
\hline 6 & FC-84/n-heptane & $\begin{array}{l}\text { Two phase } \\
\text { One phase }\end{array}$ & $\begin{array}{l}\mathrm{RT} \\
54^{\mathrm{c}}\end{array}$ \\
\hline 7 & $\mathrm{FC}-84 /\left(\mathrm{CF}_{3}\right)_{2} \mathrm{CHOH} / \mathrm{CF}_{3} \mathrm{CH}_{2} \mathrm{OH}^{\mathrm{e}}$ & $\begin{array}{l}\text { Two phase } \\
\text { One phase }\end{array}$ & $\begin{array}{l}0-\mathrm{RT} \\
26^{c}\end{array}$ \\
\hline 8 & FC-84/n-hexane $/\left(\mathrm{CF}_{3}\right)_{2} \mathrm{CHOH} / \mathrm{CF}_{3} \mathrm{CH}_{2} \mathrm{OH}^{\mathrm{f}}$ & $\begin{array}{l}\text { Three phase } \\
\text { Two phase } \\
\text { One phase }\end{array}$ & $\begin{array}{l}0^{c} \\
\sim 15-30^{c} \\
\sim 33^{c}\end{array}$ \\
\hline 9 & $n$-hexane $/\left(\mathrm{CF}_{3}\right)_{2} \mathrm{CHOH} / \mathrm{CF}_{3} \mathrm{CH}_{2} \mathrm{OH}^{\mathrm{e}}$ & Two phase & $T<60^{c}$ \\
\hline
\end{tabular}

${ }^{a}$ Reference [15a]. ${ }^{b}$ All data for a 1:1 volume ratio unless otherwise stated. ' Experimental observation; not a consolute temperature.

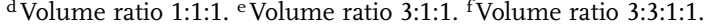

excess pressure development in closed systems, one should check the physical properties of the solvents considered for the Games (Table 14-3). When capped vials or sealed glass tubes are warmed, the safest heat source is a water bath of ca. $60^{\circ} \mathrm{C}$.

Entries 5 and 8 in Table 14-2 constitute particularly amusing systems, since all their phase transitions can be triggered by ice water and with bare hands. All phase transitions can be observed either in warming or in cooling modes. During the experiments with entries 4 and 8 , the transition temperatures can differ significantly from those listed if the experiments are performed in static mode (i.e., no rocking or shaking applied to the vials). This is caused by the screening effect of the middle phase, since the top and bottom phases should merge on warming. The latter unstable systems immediately merge on turning the vials. In some cases, heavy emulsions can be observed over narrow temperature ranges (not shown on Figure 14-4, but possible).

Tab. 14-3. Some physical properties of selected solvents

\begin{tabular}{llll}
\hline Solvent & $\boldsymbol{M p}\left({ }^{\circ} \mathrm{C}\right)$ & $\boldsymbol{B p}\left({ }^{\circ} \mathrm{C}\right)$ & Density $\left(\mathbf{g ~ m L}^{-1}\right)$ \\
\hline FC-72 & -90 & 56 & 1.68 \\
FC-84 & -95 & 80 & 1.73 \\
$n$-Hexane & -95 & 69 & 0.659 \\
$n-\mathrm{Heptane}$ & -91 & 98 & 0.684 \\
$\left(\mathrm{CF}_{3}\right)_{2} \mathrm{CHOH}$ & -4 & 59 & 1.596 \\
$\mathrm{CF}_{3} \mathrm{CH}_{2} \mathrm{OH}$ & -43.5 & $77-80$ & 1.373 \\
$\mathrm{CH}_{3} \mathrm{NO}_{2}$ & -29 & 101.2 & 1.127 \\
\hline
\end{tabular}


14.4

Name of the Games

All Games are displayed in Figures 14-2 to 14-7. The standing vials shown in the photographs correspond to $30 \%$ of actual size. Figures 14-1 to 14-5 display Games with System $3 \rightarrow 2 \rightarrow 1$; Figure 14-6 with System $3 \rightarrow 2$, middle $\rightarrow$ up version; and Figure 14-7 with System $3 \rightarrow 2$, middle $\rightarrow$ down version. Each vial is charged with appropriate amounts of the solvent mixtures shown below. Then the dyes are added and the vials sealed. More details are given under the names of the appropriate Games.

\section{System $3 \rightarrow 2 \rightarrow 1$ (cf.: Entry 8, Table 14-2)}

A mixture of $n$-hexane $(8.0 \mathrm{~mL})$, trifluoroethanol $(2.5 \mathrm{~mL}), 1,1,1,3,3,3$-hexafluoro-2-propanol $(2.5 \mathrm{~mL})$ and FC-84 $(8.0 \mathrm{~mL})$ is made at room temperature. This mixture forms three layers at ice temperature, two layers at room temperature, and a one-phase system at body temperature (Table 14-2, Figures 14-2 to 14-5).

System $3 \rightarrow 2$, middle $\rightarrow$ up version (cf.: Entry 4, Table 14-2)

A mixture of $n$-heptane $(5.75 \mathrm{~mL})$, nitromethane $(5.75 \mathrm{~mL})$ and FC-72 $(10.5 \mathrm{~mL})$ is made at room temperature. The top and bottom phases merge on heating, facilitated by gentle shaking, while the nitromethane layer goes up (Table 14-2, Figure 14-6).

System $3 \rightarrow 2$, middle $\rightarrow$ down version (cf.: Entry 4, Table 14-2)

A mixture of $n$-heptane $(10.5 \mathrm{~mL})$, nitromethane $(5.75 \mathrm{~mL})$ and FC-72 $(10.5 \mathrm{~mL})$ is made at room temperature. The top and bottom phases merge on heating, facilitated by gentle shaking, while the nitromethane layer goes down (Table 14-2, Figure 14-7).

14.4.1

Make Them Blue!

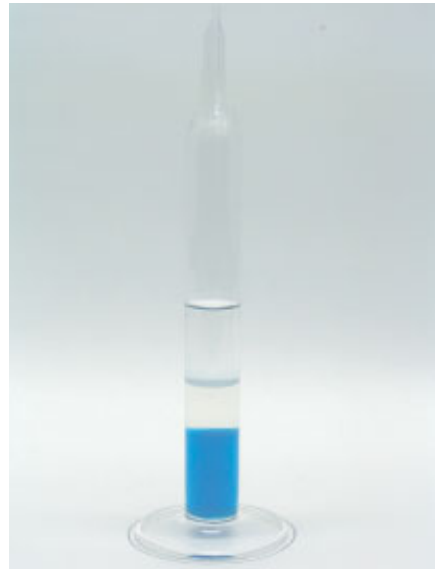

A

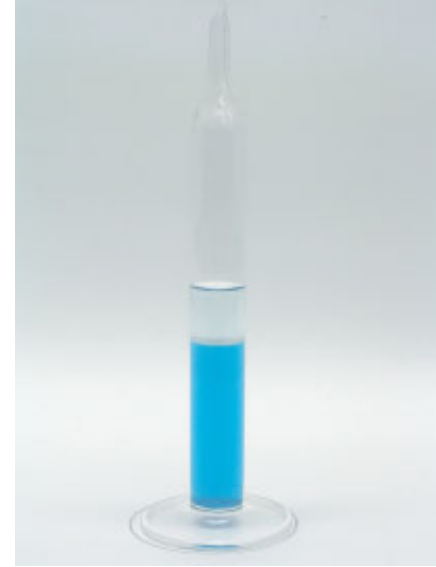

B

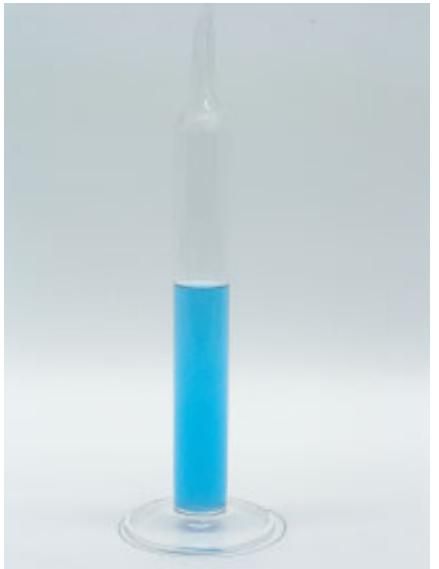

C

Fig. 14-2. Make Them Blue! 
This Game features stages of System $3 \rightarrow 2 \rightarrow 1$ in the warming cycle (cf. entry 8 , Table 2 .). The FC-84 rich layer is colored with the "blue dye", while the middle and top ones are clear and colorless (Figure 14-2A). Slight warming merges the lower layers, the blue color becomes lighter, while the hexane rich layer remains colorless (Figure 14-2B). The one-phase system formed at higher temperature is evenly dyed blue: thus the job is done (Figure 14-2C)!

14.4.2

Purple Empire

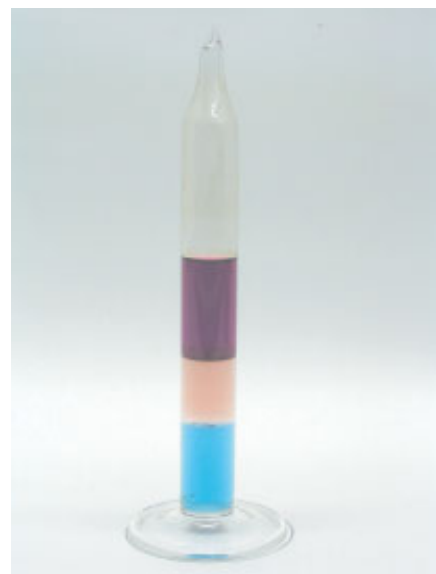

A

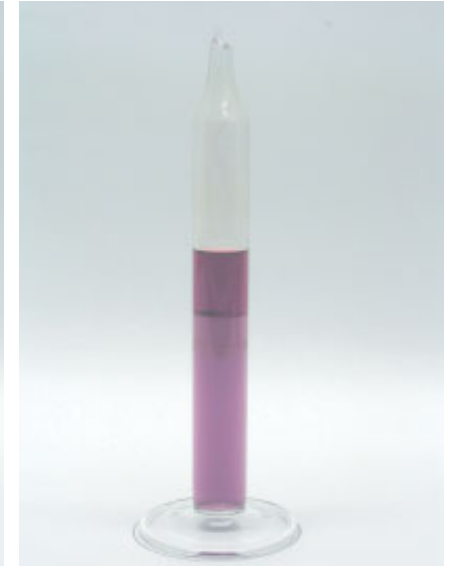

B

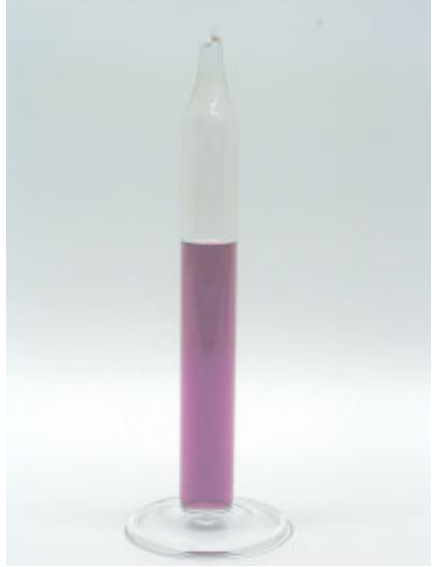

C

Fig. 14-3. Purple Empire.

This Game is a variant of the above (14.4.1), since besides the "blue dye" some iodine is added to make different colors at the three-phase condition: purple, orange-red and blue. At the two-layer stage, much of the iodine is still in the hexane rich top phase, while the color of the fluorous cobalt phthalocyanine is shaded or augmented by iodine (Figure 14-3B). Finally, all space is evenly dyed purple by iodine (Figure 14-3C).

14.4.3

Which Phase to Winter?

This Game features the stages of System $3 \rightarrow 2 \rightarrow 1$ in a cooling cycle (cf. entry 8 , Table 14-2). One series of vials contains the organophilic $\left(\mathrm{Au}_{m}\right)\left[\mathrm{HS}\left(\mathrm{CH}_{2}\right)_{11} \mathrm{CH}_{3}\right]_{n}$ dye (Figure $14-4 \mathrm{~A}, \mathrm{~B}, \mathrm{C})$; the other series contains the fluorophilic $\left(\mathrm{Au}_{m}\right)\left[\mathrm{HS}\left(\mathrm{CH}_{2}\right)_{3} \mathrm{R}_{\mathrm{f} 8}\right]_{n}$ dye (Figure 14-5A,B,C). No one can tell which is which until the three-phase stage of both series arrives. At the warm side or high temperature limit the gold nanoparticles are evenly distributed through the whole liquid volume (Figures 14-4A and 14-5A); however, at lower temperature they are completely withdrawn to the fluorine rich lower layers of the intermediate biphasic 
582 14 Fun and Games with Fluorous Chemistry

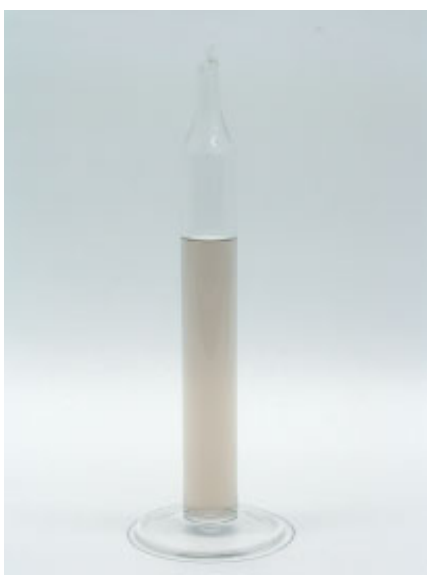

A

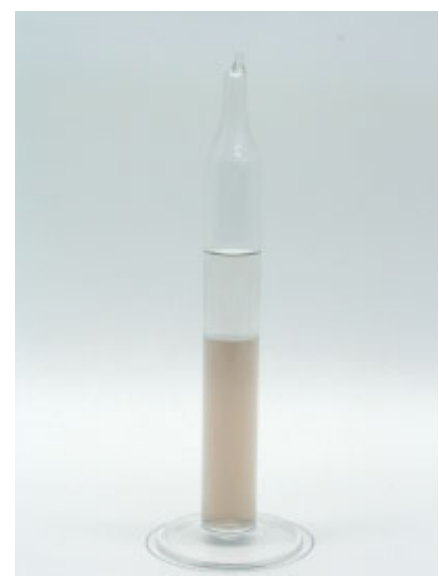

B

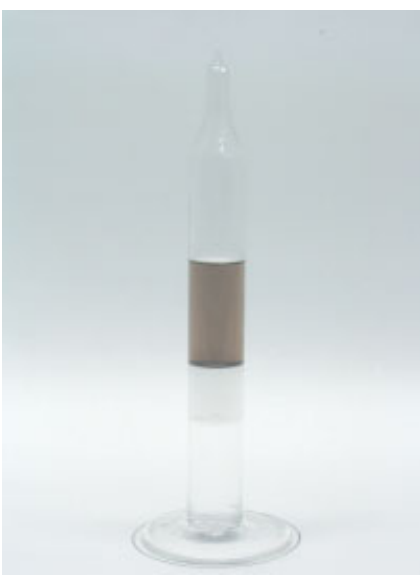

C

Fig. 14-4. Which Phase to Winter?

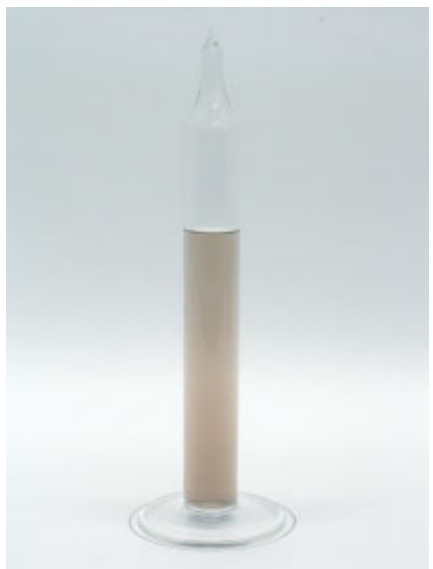

A

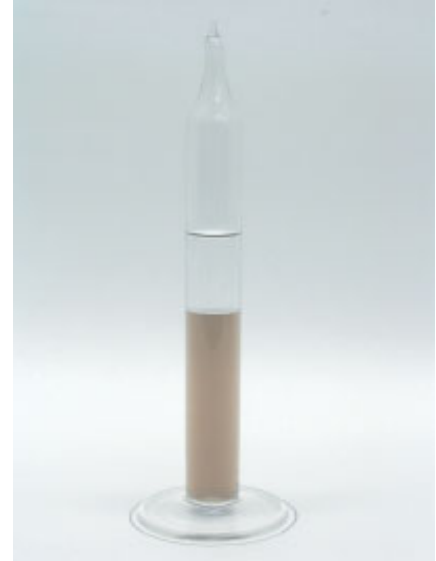

B

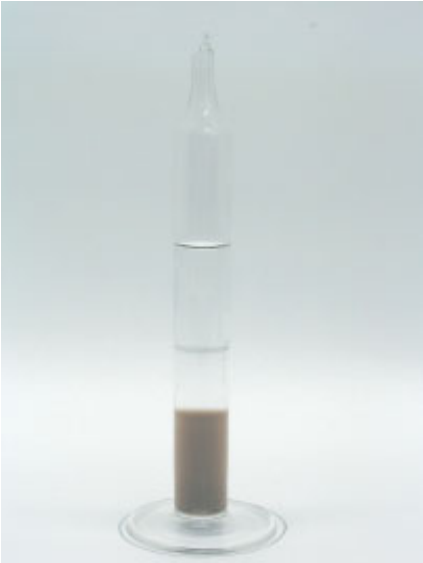

C

Fig. 14-5

systems (Figures 14-4B and 14-5B). Neither type of thiol protected gold nanoparticles remain in the hexane rich upper layer, an unexpected event for the organophilic dye (Figure 14-4B). The splitting of the bottom phases on further cooling yields the three-phase systems shown, and gives the solution to the puzzle: the gold particles select phases for wintering according to their coats (Figures $14-4 \mathrm{C}$ and $14-5 \mathrm{C}$ )! 


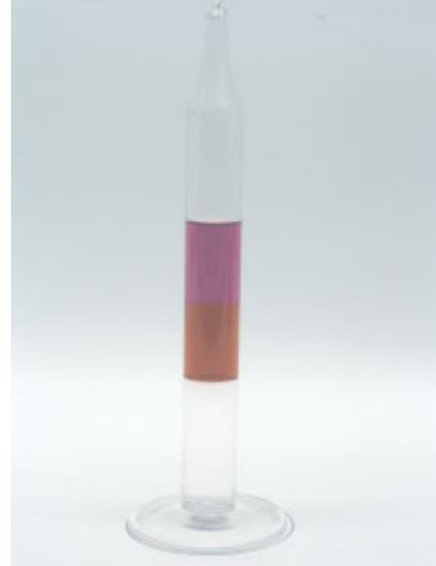

A

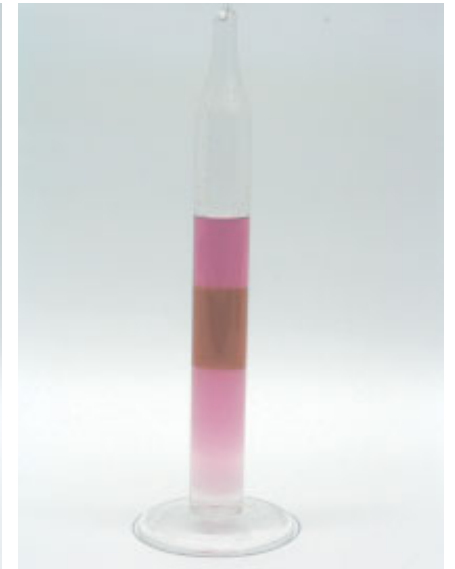

B

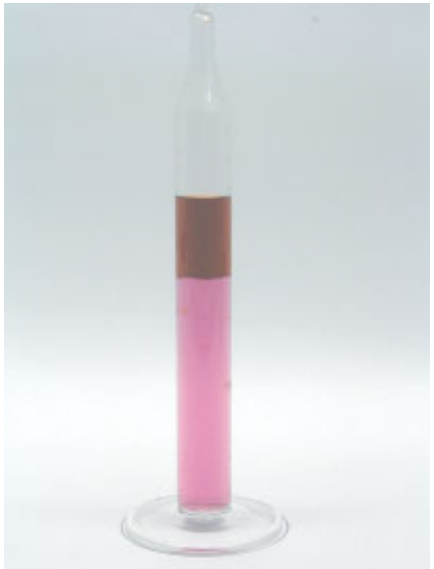

C

Fig. 14-6. Up and Down.

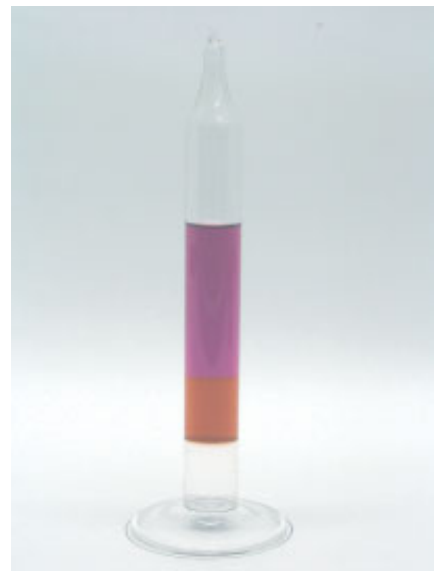

A

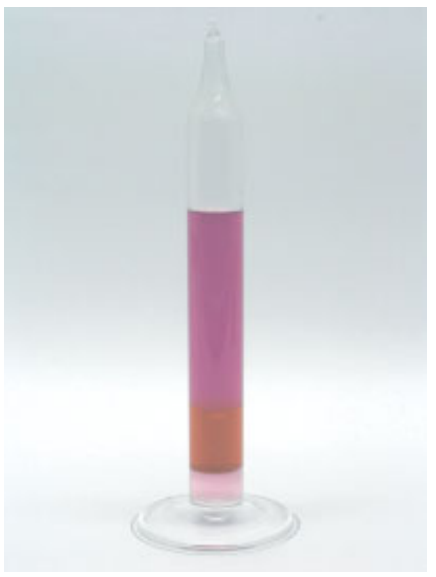

B

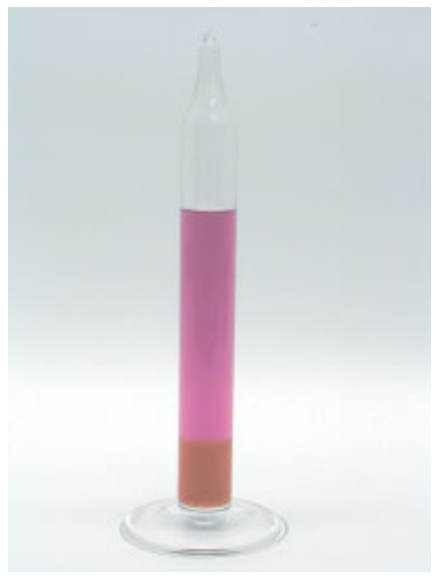

C

Fig. 14-7

This Game features the stages of System $3 \rightarrow 2$, middle $\rightarrow$ up $\left(\mathrm{C}_{7} \mathrm{H}_{16}: \mathrm{CH}_{3} \mathrm{NO}_{2}: \mathrm{FC}-72=\right.$ 5.75:5.75:10.5 v/v) and System $3 \rightarrow 2$, middle $\rightarrow$ down $\left(\mathrm{C}_{7} \mathrm{H}_{16}: \mathrm{CH}_{3} \mathrm{NO}_{2}: \mathrm{FC}-72=\right.$ 10.5:5.75:5.75 v/v) in their warming cycles (Figure 14-6A,B,C and Figure 14-7A,B,C; cf. entry 4, Table 14-2). The density of the merged heptane/FC-72 phases is tuned by volume ratios to be higher/lower than that of $\mathrm{CH}_{3} \mathrm{NO}_{2}$. This results in the up and down movements of 
the $\mathrm{CH}_{3} \mathrm{NO}_{2}$ layers upon phase transitions. The partition and the extent of solvation of the iodine used for dying the layers improves the beauty of the Game. Moreover, in an undisturbed cooling cycle special phenomena can be observed. The top phase releases small droplets, which penetrate through the screening $\mathrm{CH}_{3} \mathrm{NO}_{2}$ phase to the bottom, until an equilibrium is established; at the same time, the droplets from the bottom phase move in the opposite direction (Figure 14-7B). A magic "F-fun" can be observed if the tubes are kept with two hands in a horizontal position and smooth waves generated by minute up and down movements (not shown).

14.5

Epilogue

In the closing pages of this book, the author wishes to pay tribute to the many pioneers of organofluorine chemistry. Their contributions, brought to fruition in both academic and in industrial research laboratories, established the vast knowledge base available today and made the advances described in this book possible [18-20].

\section{Acknowledgements}

The author thanks Ana-Maria Bonto and Dr. Peter Ivanko for their careful experimental assistance, László T. Mika for the included drawing and photographs, and the European Contract of Research Training Network ("Fluorous Phase" HPRN-CT-2000-00002) for financial support.

\section{References}

1 Hildebrand, J. H.; Cochran, D. R. F. J. Am. Chem. Soc. 1949, 71, 22-25.

2 Sсотт, R. L. J. Am. Chem. Soc. 1948, 70, 4091-4093.

3 For solubility of iodine in perfluoro- $n$ heptane or in organosilicon compounds, see: (a) Benesi, H. A.; Hildebrand, J. H. J. Am. Chem. Soc. 1948, 70, 3978-3981.

(b) Shinoda, K.; Hildebrand, J. H. J. Phys. Chem. 1957, 61, 789-793, resp.

(c) For the anomalous behavior of fluorocarbon solutions, see: ScotT, R. L. J. Phys. Chem. 1958, 62, 136-145. (d) For anomalies in Lennard-Jones type attraction or repulsion potentials for large fluorocarbon molecules, see: SмITH, E.; Hildebrand, J. H. J. Chem. Phys. 1959, 31, 145-147.

4 Bartel-Rosa, L. P.; Gladysz, J. A. Coord. Chem. Rev. 1999, 191-192, 587-605.

5 Kiss, L. E.; Kövesdi, I.; Rábai, J. J. Fluorine Chem. 2001, 108, 95-109.
6 Rábai, J.; Bonto, A.-M.; Miedziák, M.; SzABó, D. The First International Sibirian Workshop - Advanced Inorganic Fluorides 'INTERSIBFLUORINE-2003' April 2-4, 2003. Novosibirsk, Russia. Proceedings of ISIF-2003. pp. 198-201. ISBN 5-90168804-5 E.

7 Gladysz, J. A. Science 1994, 266, 5556.

8 Smart, B. E. J. Fluorine Chem. 2001, 109, $3-11$.

9 (a) No author specified. British Patent 840,725 (Minnesota Mining and Manufacturing Company) July 6, 1960 (application: August 12, 1955); Chem. Abstr. 1961, 55, 6496h. (b) Tiers, G. V. D. US Patent 3,281,426 (Minnesota Mining and Manufacturing Company), October 25, 1966 (application: August 12, 1955, and May 1, 1961); Chem. Abstr. 1967, 66, 66740k. (c) Tiers, G. V. D. J. Am. Chem. Soc. 1960, 82, 5513. 
10 15th International Symposium on Fluorine Chemistry, Vancouver, Canada, August 1997.

11 Brace, N. O. US Patent 3,271,441 (E. I. du Pont de Nemours and Company), September 6, 1966 (application: June 18, 1962); Chem. Abstr. 1967, 66, 2388y.

12 Knunyants, I. L; Shokina, V. V. U.S.S.R. Patent 156,555 August 28, 1963 (application: July 26, 1962). Chem. Abstr. 1964, 60, 6792f.

13 von Werner, K. German Patent 3,247,728 (Hoechst A.-G.), July 5, 1984 (application: December 23, 1982); Chem. Abstr. 1985, 102, 5889f.

14 Horváth, I. T.; RÁbaI, J. Science 1994, 266, 72-75.

15 Unpublished results, Eötvös Loránd University, of (a) BonTo, A.-M., and (b) IVANKo, $P$.

16 Friediander, W. M. US Patent 3,088,849
References

(to Minnesota Mining and Manufacturing Company), May 7, 1963 (application: December 11, 1961). Chem. Abstr. 1963, 59, 11258b.

17 Brust, M.; Walker, M.; Bethell, D.; Schiffrin, D. J.; Whyman, R. J. Chem. Soc., Chem. Commun. 1994, 801-802.

18 Fluorine: The First Hundred Years (18861986). Banks, R. E.; Sharp, D. W. A.; Tatıow, J. C. Eds. Elsevier Sequoia, New York, 1986.

19 Hudlicky, M. Chemistry of Organic Fluorine Compounds, A Laboratory Manual with Comprehensive Literature Coverage, 2nd (Revised) Edition, Ellis Horwood, New York, 1992.

20 Chemistry of Organic Fluorine Compounds II. A Critical Review. ACS Monograph 187. Hudlicky, M.; Pavlath, A. E. Eds. American Chemical Society, Washington, DC, 1995. 